REST Journal on Emerging trends in Modelling and Manufacturing
Vol: 7(2), 2021
REST Publisher
ISSN: 2455-4537

\title{
A Review on the Multi Objective Optimization in Turning Operation of SS304 Sheet Metal Component
}

\author{
N. J. Rathod ${ }^{1}$, Dr. M. K. Chopra ${ }^{1}$, U. S. Vidhate ${ }^{2}$ \\ ${ }^{1}$ Department of Mechanical EngineeringSarvepalliRadhakrishnan University, Bhopal, India, \\ ${ }^{2}$ SMPEngineers and Electricals PVT. LTD., Nashik, India, \\ rathodnikhil358@gmail.com, Indiachopramk62@yahoo.co.in, umeshvidhate30@gmail.com
}

\begin{abstract}
The impact of cutting parameters in the confronting procedure for the most part influences the Tool life and Production time of item. The developing rivalry for higher profitability with great surface finish has made the need of utilizing top notch machining instrument. The significant cutting parameters in confronting process chiefly cutting speed, feed rate, depth of cut influence the Tool life and Production time of the completed material. This paper reviews the streamlining of cutting parameters in confronting process utilizing Taguchi method. An exceptionally structured symmetrical exhibit of Taguchi is utilized to examine the impact of slicing parameters through the modest number of analyses. Taguchi technique is an integral asset of improvement. ANOVA is utilized to discover which input parameters altogether influence the execution attributes. Sign to Noise $(\mathrm{S} / \mathrm{N})$ proportion is utilized to gauge the varieties of test information.
\end{abstract}

\section{Introduction}

Turning is a machining procedure used to get the ideal element of round metal. The primary objective in present mechanical period is to create minimal effort quality item with required measurements in an optimum time.Therefore, the optimum cutting parameters are to be perceived first. In turning, the metal is in rotational movement and a cutting tool is utilized to shear away the undesired metals. This procedure requires lathe machine or turning machine, cutting tool, work piece and fixture.The work piece is fixed in the machine chuck and is pivoted at rapid. The cutting tool is taken care of in corresponding to the hub of turn. During this machining procedure the cutting parameters profoundly relies on the work piece, cutting tool material, and so on. These are dictated by understanding or machine catalogue.Surface roughness, Tool life and machining time is a widely used attribute of product quality and in most cases a technical necessity for mechanical products. Thus the optimum selection of cutting parameters such as feed rate, depth of cut, cutting speed, etc, generates optimum conditions during machining and becomes the main exigency of manufacturing industry.Surface roughness, Tool life and machining time is an important criterion to find the quality of a surface. It is an important response parameter. In machining process various parameters are: Input Parameters: Cutting speed, Feed rate, Depth of cut, Insert radius, Cutting fluid, etc. Output Parameters: surface roughness, Tool life and machining time.

\section{Literature Review}

Several experimental investigations have been carried over the years in order to study the influence of various cutting parameters on the surface finish of the work piece, tool life using work pieces of different materials.

AhmetHasçalık et al. [1]In this examination, the impact and optimization of machining parameters on surface roughness and tool life in a turning activity was examined by utilizing the Taguchi method. The trial examines were led under changing cutting speeds, feed rates, and depths of cut. An symmetrical cluster, , the signal-to-noise $(\mathrm{S} / \mathrm{N})$ ratio, and the analysis of variance (ANOVA) were utilized to the investigation the presentation attributes in the turning of business Ti6Al-4V compound utilizing CNMG 120408-883 supplement cutting tool. The ends uncovered that the feed rate also, cutting speed were the most powerful factors on the surface roughness and tool life, respectively. The surface roughness was primarily identified with the cutting speed, while the pivotal axial depth of cut had the best impact on tool life.

HamdiAouici et al. [2]The current examination, intends to research, under turning states of solidified AISI H11 (X38CrMoV5-1), the impacts of cutting parameters on flank wear (VB) and surface roughness (Ra) utilizing CBN device The machining experiments are conducted based on the response surface methodology (RSM). Joined impacts of three cutting parameters, in particular cutting speed, feed rate and cutting time on the two execution yields (for example VB and $\mathrm{Ra}$ ), are investigated utilizing the examination of change (ANOVA). Ideal cutting conditions for each execution level are built up and the relationship between the factors and the innovative parameters is resolved utilizing a quadratic regression model. The outcomes show that the flank wear is impacted basically by the cutting time and in the second level by the cutting speed. Additionally, it is that demonstrated that the feed rate is the prevailing variable influencing work piece surface roughness.

Asutosh Panda et al. [3]The paper tends to the appraisal, displaying, and optimization investigation of surface roughness in finish dry hard turning (FDHT) of AISI 4340 steel with covered artistic instrument by thinking about the cutting speed, axial feed, depth of cut, and nose radius as machining parameters. Thirty arrangements of longitudinal turning preliminaries dependent on central composite (CCD) structure of tests (DOEs) are performedresponse surface 
methodology (RSM particle swarm optimization (PSO), lastly, Gilbert's methodology are accordingly applied formathematical modelling, response optimization, tool life estimation, and economic analysis.. Additionally, various diagnostic tests have been executed to check the statistical significance and validity, adequacy, effectiveness, and fitness of data of the proposed model using analysis of variance (ANOVA) and Anderson-Darling normal probability test. Results indicated that nose radius and feed are the most significant controlled as well as dominant factors for hard turning operation if the minimization of the machined surface roughness is considered.

Samir Khamel et al. [4]The primary of the current examination is to research the impacts of cycle boundaries (cutting speed, feed rate and depth of cut) on execution qualities (tool life, surface roughness and cutting forces) in finish hard turning of AISI 52100 bearing steel with CBN tool. The cutting forces and surface roughness are estimated toward the finish of helpful tool life. The joined impacts of the cycle boundaries on execution qualities are researched utilizing ANOVA. The composite allure advancement procedure related with the RSM quadratic models is utilized as multiobjective optimization approach. The outcomes show that feed rate and cutting speed emphatically impact surface roughness and tool life. However, the profundity of cut shows greatest effect on cutting powers. The proposed test and measurable methodologies carry dependable strategies to show, to advance and to improve the hard turning process. They can be expanded productively to consider other machining measures.

A. T. Abbas et al. [5] High-quality prepares are utilized in different regular citizen and military items. The underlying expense of the crude materials for these items is exceptionally high. The surface roughness of these items is critical during the completing go to be acknowledged during the last assessment. The surface roughness ought to adjust to the necessary qualities expressed on the plan drawing. The paper presents the aftereffects of trials in turning of highstrength steel highlighting three variables - cutting speed V, feed rate $\mathrm{f}$, and depth of cut $\mathrm{t}$ - on five levels (125 examples). These were partitioned into 25 gatherings. Every one of the five gatherings was exposed to one basic machining speed. Each gathering was machined utilizing five degrees of cutting speed. Every profundity was handled utilizing five degrees of feed rate. Tessa was utilized for assessment of surface roughness. There is minimal current exploration on machining high-quality steel. The significant expense of this material urges us to search for the ideal going conditions to accommodate the predefined roughness of surface Ra and the base machining season of unit volume Tm. Because of our study, an artificial neural network was planned in Matlab on the premise of the MLP 3-10-1 multilayer perceptron that permits us to foresee $\mathrm{Ra}$ of the work piece with $\pm 2.14 \%$ precision inside the scope of the test cutting speed, depth of cut, and feed rate esteems. Just because, a Pareto boondocks was acquired for $\mathrm{Ra}$ and $\mathrm{Tm}$ of the completed work piece from high-quality steel utilizing the artificial neural network model that was later used to decide the ideal cutting conditions.

SitkıAkıncıoğlu et al. [6]In this examination, Taguchi method has been applied to assess the impact of cryogenically treated devices in turning of Hastelloy C22 super combination on surface roughness. The optimum parameters (cryogenic treatment, cutting speed, and feed rate) of turning were dictated by utilizing the Taguchi method test plan technique. In Taguchi technique, L9 symmetrical cluster has been utilized to decide the the signal noise (S/N) ratio. Examination of ANOVA was done to recognize the noteworthy elements influencing surface roughness. The measurable examination showed that feed rate, with a commitment rate as high as $87.64 \%$, had the most predominant impact on machining execution, trailed by the cryo-treated apparatuses treatment and cutting speed, individually. The affirmation tests demonstrated that it is conceivable to improve surface roughness altogether by utilizing the Taguchi method. Surface roughness was improved by 28.3 and $72.3 \%$ by shallow (CT1) cryogenic treatment and profound cryogenic treatment (CT2) applied on cementite carbide instruments (UT). It found that wear opposition of tungsten carbide embed was expanded by shallow and profound cryogenic medicines.

Ramanuj Kumar et al. [7]The current investigation concentrated on numerical displaying, multi response optimization, tool life, and conservative investigation in finish hard turning of AISI D2 steel utilizing CVD-coated carbide and uncoated carbide embeds under dry natural conditions. Regression methodology and the grey relational methodology were executed for demonstrating and multi response optimization.Comparative economic statistics were carried out for both inserts, and the adequacy of the correlation model was verified. The test and anticipated qualities for all reactions were exceptionally near one another, suggesting the importance of the model and demonstrating that the correlation coefficients were near solidarity. The observed tool life for the covered carbide embeds was multiple times higher than that for the uncoated carbide embed, considering flank wear. The chip volume in the wake of machining for the covered carbide embed was 26.14 occasions higher than that of the uncoated carbide embed and could be better used for higher material expulsion rate Abrasion, diffusion, notching, chipping, and built-up edge have been observed to be the principal wear mechanisms for tool life estimation. Use of the covered carbide apparatus decreased machining costs by about 3.55 occasions contrasted with the utilization of the uncoated carbide embed, and gave financial advantages in hard turning.

Miguel MandúBonfá et al. [8]The fundamental target of this work is to assess the tool life and the work piece surface roughness while applying a vegetable-based cutting liquid by least amount of oil (MQL) at three distinct bearings in turning AISI D6 solidified steel with polycrystalline cubic boron nitride apparatuses with Al2O3 artistic cover and TiNcoating. Tool wear investigations were performed on the instruments toward the finish of their lives inside a filtering scanning electron microscope. The use of the cutting liquid by MQL procedure toward the path between the principle apparatus flank face and the work piece indicated preferable outcomes over the dry condition. The use of MQL through different headings likewise indicated serious outcomes. Scraped spot and attachment were the predominant systems for the wear of the tools. 
NivaldoLemosCoppini et al. [9]Based on the experiments performed in this work, it very well may be presumed that for inside turning of sintered carbide parts with PCD tools, in conditions like those utilized here Internal turning accomplished surface roughness esteems like those typically got in crushing activities what's more, subsequently, may supplant crushing in mechanical measures. To acquire a protected cycle, i.e., a cycle without unexpected breakage of the front line in the start of tool life, it is important to utilize not all that little cutting speed and not all that high feed. At the point when the most noteworthy cutting speed was utilized, the expansion of feed caused the quantity of slicing goes before the bleeding edge breakage to diminish and the work piece surface roughness to increment.

SanjeevSaini et al. [10]Significant sign of surface quality on machined parts is surface roughness. There are different machining parameters which affect the surface roughness, yet these impacts have not been enough measured. With the goal for producers to expand their benefits from using finish hard turning, precise prescient models for surface roughness and tool wear must be developed. This paper uses reaction surface strategy (RSM) for displaying to anticipate surface roughness and tool wear for assortment of cutting conditions in finish hard turning. The exploratory information acquired from performed tests in complete the process of turning of solidified AISI H-11 steel have been used. Lessening in feed rate and cutting speed up brought about noteworthy increment in surface quality. Notwithstanding, cutting speed up likewise delivered generally higher tool wear. Additionally profundity of cut didn't altogether influence the tool wear and surface roughness.

T. Tamizharasan et al. [11]Hard turning is a profitable alternative to finish grinding. The ultimate aim of hard turning is to remove work piece Material in a single cut instead of a lengthy grinding procedure to minimise processing time, production costs, surface Roughness and setting time, and remaining competitive. Recently Years, interrupted hard turning, which is the process of turning hard parts with interrupted surface areas, has also been observed Were welcomed. The hard turning process offers many possible advantages compared with conventional grinding operation. In addition, wear of the tools, life of the tools, surface quality turned and amount of material removed are also predicted. In the analysis, 18 Different machining conditions, three grades of Cutting tool Polycrystalline cubic boron nitride (PCBN), is considered. This paper describes the different features in terms of Ability of components, life of the tools, and wear of tools, effects of individual components Tool life and material removal conditions, and economics of Work.

Jing Sheng et al. [12]The relation between the wear of cutting tools and In the machinery the machining parameters were the priority Place of production. A computational process in this investigation coupling on the basis of minimum cutting tool wear was proposed for the turning parameters. Wear of the cutting instrument, separated by the machined surface area was considered an assessment standard in the experiment. The connexion between cutting Speeds and temperatures, and the variation of Parameters and temperatures for the cutting have been discussed. Therefore the optimum cutting temperature was discovered at which the Wearing a cutting tool had the slightest meaning. The Method It was obtained between the temperatures and cutting parameters with orthogonal experiments and the coupling of the cutting parameters, the minimum wear was thus calculated Cutter. Furthermore the processes for reduced wear Cutter analyses were carried out according to the characteristics of Wear cutting tool. The research would be of interest to Creating a Cutting database of metal materials.

P. Sivaiah et al. [13]Texture tools were successfully produced with Laser Engineering. Impact of newly developed cutting tool Temperature, wear of tool fank, and surface roughness analysed for different cutting under MQL conditionSpeed conditions. Positive outcomes from the study wereUnder MQL framework, observed in hybrid method. Important reduction in temperature of the cutting zone with Hybrid texture tool shows low friction built on contact region. Few surface defects indicate by using hybrid texture method Stable framework for cuts. The hybrid texture tool brought more life to the tool due to the improved protection of the lubrication sites. Developed hybrid tool significantly reduced cutting temperature, wear of tool fanks and surfaces roughness AISI 304 steel material turned under MQL Condition respectively over single texture pattern tool. Industries which work on AISI 304 steel could therefore Use these hybrid tools to create profitable business with working conditions considered. The cooling technique with MQL greatly reduced the leakage of coolant into the environment. So hybrid formed The MQL method eliminates the adverse effects of using Conventional refrigeration technique during difficult machining Fabrics. New approach to cooling which supplies MQL mist meets the environmentally friendly switching on hybrid method from steel material AISI 304.

Mozammel Mia et al. [14]The effects of the hardness of the materials andHigh pressure refrigerant jet over dry machining is assessed inCompliance with surface roughness and temperature cuts usingL36 orthogonal Taguchi array. The experimental data were analysed using cumulative empirical distribution function, andBox plot with regard to hardness of the material and the machining environment. Following that, maximising the output responses carried out with signal-to noise ratio. The "smaller is better" was adopted as an optimization component of Taguchi optimization Principle; experiment architecture applied to parameters Guidance, and analysis of variance were used to assess the effects of control variables. Three types of hardened steels for present experimental studies were turned by an insert of coated carbide at Industrial combinations of speed - feed under both dry and high-pressure jet coolants. Cutting range, being a less important Parameter, remained unchanged. The high pressure refrigerant jet was Find effective in temperature reduction, surface area Roughness, and tool wear. Statistical analysis revealed the hardness of the substance working is the most critical factor for both Temperature cutting and roughness to the surface. Other variables, however, made a very similar contribution to surface roughness when deciding the cutting temperature Environment has shown crucial position. 
D.K. Ojha et al. [15]The traditional tool life estimation methods take Long time and use a lot of content for job bits. Under this Paper, a faster tool life estimation method which requires less consumption of work piece material is proposed and there are methods. In this process the life of the tool is calculated by fitting a best-fit line for data dropping in a steady wear zone and seeking time to extrapolation method failure. Neuronal networks Used to forecast system estimates lower, upper and more likely Life. Comparison among neural networks and multiple regressions shows the former's superiority. Also the paper proposes Continuous tracking technique of product use in the shop Floor and tool life estimates are revised / obtained based on the Feedback to shop floor.

Muhammad Younas et al. [16]As for Ti6Al4V machining, the main responses that was considered as a conflicting pattern in this study regarding the conditions for cutting inputs. Optimum parameters have been obtained by means of multi-objective optimisation of all those responses to the sustainable manufacturing target Items for the automotive and aerospace applications.

Denis Boing et al. [17]The perfect scenario for carrying out a machining process is to be able to predict the efficiency of the tools without the need todo practical experiments. However, each set of machining conditions is unique in an industrial setting, since the conditions of the machine tool, the machined material, the cutting tool and the fixture system which differ. This can trigger discrepancies between the Values forecasted. In this context, the purpose of this research was to demonstrate and discuss a performance test for tools Methodology and tool-life prediction model using the 3D wear parameter WRM applied with PCBN tools for rough turning. The methodology adopted and the model developed reflect a substantial time reduction in the experimental machining tests, Simplifying research and development of cutting tool grades, as well as optimization of the machining process.

S.P. Palaniappan et al. [18]This paper explores the machining of Aluminium 6082 alloy experimentally to determine the optimum CNC turning-process parameters. An experimental plan based on the L27 orthogonal array was drawn up and turning experiments with prefixed cutting parameters for Aluminium 6082 were conducted tungsten carbide cutting tool. The spindle speed, feed rate and depth of the turning parameters were Using Taguchi and ANOVA, cut for surface roughness and material removal rates And the chip temperature for each experimental condition also contrasted.

Manu Ravuri et al. [19]To improve process parameters for the quality of the product, play a very important role. The branches are to produce more components with an adequate quality with a minimum of time and quantity. The demand for high carbon steels is growing nowadays, as the strength of high carbon steel is increased high as these are mainly used in manufacturing, since their implementations are extremely vast. At the EN 31 gun tentative are used. L27 Orthogonal array used for DOE to research the impact of process parameters such as Rpm, Feed; cutting depth, and nose radius were based on surface roughness. 3 levels are considered for each parameter. It has been used to perform CNC lathe machine experiments and to find surface roughness count surface instrument. The authors made an attempt in this respect and proposed the optimised procedure Set parameters. Short-term test method for defining machinability and face turning process is proven Optimized Parameter of the operation.

Mustafa Kuntog lu et al. [20]Online monitoring of tool wear and tool breakage is very important in order to reduce production costs via Optimisation of parameters for machining. Increasing cutting forces affect the quality of the work piece and its tools Condition that is the ultimate goal of manufacturing line and progressive tool wear that can trigger the tool breaking. Method Taguchi is used extensively to evaluate the number of experiments while Analysis of variance (ANOVA) addresses the parameter(s) are / are successful at the output. This research involves experiments and optimization processes with 3 input parameters during turning of AISI 1050 material (cutting speed, feed rate, tip tool) using Taguchi process. For the determination of the cutting tool state, Tangential cutting force and acoustic emission (AE) measurements were performed during metal Delete. ANOVA results showed that cutting speed is about 45 per cent the most powerful and the tip of the knife is Second on tool wear around 35 per cent.

IlhanAsiltürk et al. [21]This study focuses on optimising turning parameters to minimise surface roughness based on the Taguchi process. The experiments were carried out using the L9Orthogonal collection in a computer to transform CNCs. Stable turning tests are conducted on hard AISI 4140 with carbide cutting tools which are coated. The statistical methods of signal to noise ratio and analysis of variance are used to investigate the effects of cutting speed, feed rate and depth Cut to rough surface. Results of this study suggest that the most important impact of feed rate is on Ra and Rz. Including the consequences of the feed's two-factor interactions Rate-cutting speed and cutting velocity depth seem significant. The ones produced Type can be used in the metalworking industry to determine optimum Initial surface roughness parameters cut.

D. Philip Selvaraj et al. [22] In this work the parameters of the dry turning of two different grades of alloyed duplex nitrogen in oxidable steel is optimised with Taguchi method. It carried out the turning operations out with carbide coated TiC and TiCN inserts. The parameters to cut Using signal to noise ratio and variance analysis, are optimised. The Cutting Effect Speed and feed rate were analysed for surface roughness, cutting force, and wear of the tools. The Results showed that the feed rate is the more important parameter that influences the surface Roughness, and power to cut. The speed of cutting was identified as the more significant Parameter which affects the wear of the tool. Using scanning electron, tool wear was analysed Image with microscope. The confirmation tests are performed under optimal cutting conditions.

Murat Sarıkaya et al. [23]The effect of cutting fluids on health, the environment and the manufacturing sector has been documented in machining operations such as rotating, friction, drilling, etc. Roughness of the surface is popular quality measure for process machining processes., The effects of process parameters on surface quality are very difficult to evaluate in all activities of spinning. The design of experiments was used in this study to research the effect of the 
Significant turning parameters such as cooling state, cutting speed, feed rate and cutting depth on average arithmetic roughness $(\mathrm{Ra})$ and average maximum profile height $(\mathrm{Rz})$ when turning AISI 1050 Rock. Results suggest feed rate on surface roughness is the most powerful parameters. Cooling conditions on roughness of the surface are dramatically efficient. The MQL is a good tool for improving the consistency of the machined surface for cutting operations.

W.H. Yang et al. [24]The Taguchi process, a powerful tool for developing quality optimisation, is used in this study to find the optimum cutting Switch process parameters. An orthogonal series, the signal to noise ratio and the analysis of variance Using tungsten carbide cutting instruments, are used to investigate the cutting properties of S45C steel bars. By this study, It is not only possible to obtain optimal cutting parameters for turning operations, but also the main cutting parameters which affect Cutting performance can be found in turning operations. There are experimental results to confirm the effectiveness of this approach.

Murat Sarkkaya et al. [25]This paper examined the use of the Taguchi-based GRA for Optimize parameters of the MQL process, such as fluid cutting; Flow rate and cut speed with multiple-performance features such as tool wear patterns and surface roughness. GRA and Taguchi's signal to noise ratio has been used to model multiple responses. Analysis of Variance was used to evaluate the Factors influence on GRG. To formulate the answers, surface response models were established with interaction.

NilrudraMandal et al.[26]The Taguchi process and Regression analysis were used in this study to assess the machinability of AISI 4340 steel with newly formed ceramic Zirconia Toughened Alumina (ZTA) Inserts. Several experiments were performed using orthogonal array L9 ofThree parameters at 3 levels. It was observed that cut depth has maximum Contribution on wear of the equipment. It developed the mathematical model of flank wear using regression analysis as a function of the independent variables listed above. The predicted value is derived from the model developed and the experimental values Very similar to each other which confirm the model's significance.

Ashok Kumar Sahoo et al. [27]This paper presents the effect of process parameters such as speed, feed and depth cutting from cutting on flank wear ( $\mathrm{VBc}$ ) and surface roughness ( $\mathrm{Ra}$ ) in turning $\mathrm{Al} / \mathrm{SiCp}$ metal matrix composites using uncoated carbide insert in dry conditions. The Experiments They was performed on the basis of the orthogonal Taguchi L9 array. Abrasion and adhesiveness Observed to be the key wear mechanism from tool tip photos. No Tool Premature Chipping and fracturing loss was observed and machining with carbide was steady Insert. Insert. Constructed edge forming is observed at low and higher cutting speeds and at high feed it adversely affected combination and consequently surface quality.

R. Suresh et al. [28]In the present study Effective multilayer coatings on cemented carbide substrate using chemical substrate Vapor deposition was tested for the machining of hardened steel AISI 4340. An Try to evaluate the impact of process parameters on machinability Aspects which use Taguchi technique. Surface plots are created to study the Interaction effects of cutting conditions on factor machinability. Correspondences were multiple linear regression models developed. On validation checks, the linear regression models were validated. Results review showed that the optimal combination of low feed rate and low cutting depth with high cutting speed is advantageous for reducing force in machining. Higher feed rate values are required to reduce the real cutting power.The wear of machining strength and tool cutting increases almost linearly can cut speed and feed rate. A mix of low and high feed prices the cutting speed is required to reduce roughness of the surface. Abrasion was the wear mechanism which was observed at all cutting conditions.

Abram Pleta et al. [29]In this paper the Taguchi approach was used to understand the Influence of machining parameters and parameters of the tool route on machining outputs as regards machining force and tool flank wear. It used to be it was found that the nutational and rotational concentrations had the greatest interactions with both the cutting forces and the wear on the tool flank. The depth of Machining affected area was also done in both radial and axial directions In this analysis, investigated where the chip thickness and Tool wear improves plastic deformed and elongated profundity Grains with radial as well as axial orientations.

M. Anthony Xavior et al. [30]Experiments involving cementitious carbide inserts and AISI 304 inoxidable steel work material with different machining parameters and three different cutting fluids Acted Conducted. Fluid shortening was considered essential Parameters along with cutting in the machining process speed, feed rate, and cutting depth. Analysis of Variance was made, and the feed rate was found to have wider effect on surface roughness and cutting speed affects the wear of the tool more. It was also found that cutting fluid has a certain volume significant effect on both surface roughness and tool wear. Efficiency of cutting fluids to minimise toola comparison of the relative output was found to wear and improve surface finish. The coconut oil has been found in general to be more fluid to cut than traditional mineral oilsReduces wear and roughness of the tool board.

Dong Min Kim et al. [31]Amicro patterned insert results in lowering of cutting power, friction coefficient and wear of the tool. That's it Study prepared a tool rake surface pattern using layer-by - layer electric discharge machining. Hard turning by calculating cutting forces and morphologies of the chips was investigated. There was friction Calculated by continuous simulation and saw-chip design, with different feed rates and surface speeds. The wear of the tools was measured using the increased rate of material removal. The insert is micro patterned the force decreased compared to the non-patterned insert, since the friction was Reduced with feed rate and surface velocity decreases. In contrast, the flank is Wear for the micro patterned insert improved by compared to the non-patterned insert as declined surface velocity. Air gaps on the micro 
patterned insert contribute to reduced friction for additional shear deformation, wear particles escaping into gaps, minimising the contact area of the shear Tool-chip, and uniform stress on touch.

\section{Discussion And Inferences Drawn From Literature Survey}

After reviewing and analyzing all above literatures we have found that Spindle speed contributes more in hard turning irrespective of the response variable. Spindle speed affects approx. 81.48\% on hard turning. After speed, feed contributes more in deciding the quality of finished product and optimizing response variable. Contribution of feed rate is as up to $70.37 \%$. Depth of cut and material hardness also affect the hard turning operation as approx. $22.22 \%$ and $11.11 \%$ respectively. Also, there are some other parameters like MRR, cutting force and rake angle each affecting less than $10 \%$ the operation.

Literatures are mainly focused on optimizing tool life, surface finish and tool wear. Around $44.44 \%$ of literature reviewed above focus on tool life optimization and same is the case for surface finish i.e. 44.44\%. For tool wear we have around $11.11 \%$ of articles reviewed.

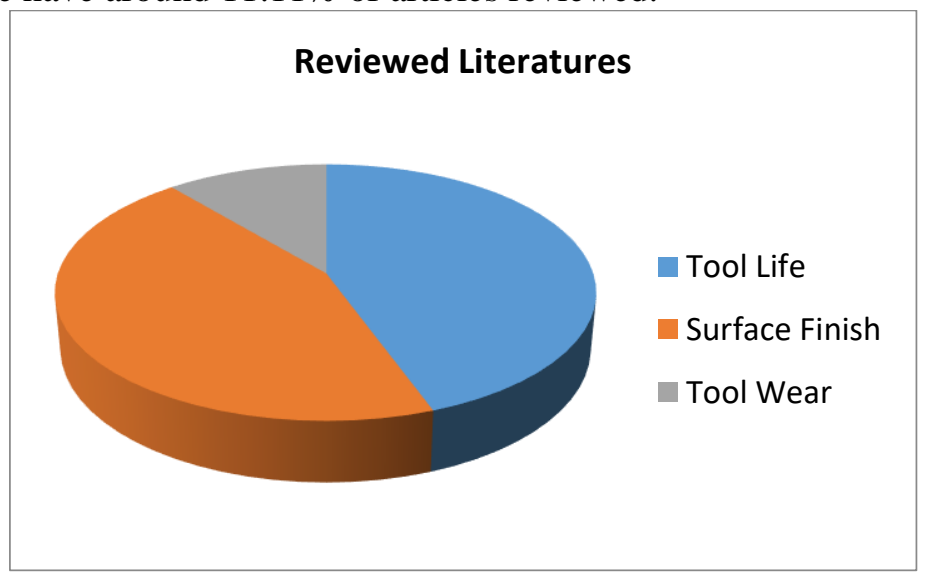

Fig. 1 Percentage wise distribution of literatures reviewed for different objectives.

While our prime focus is on optimizing the tool life for hard turning we have reorganized all the results from the literatures and found that speed, feed and depth of cut are the main focused parameters while other parameters like MRR and cutting force also affects the tool life.

TABLE 1. Effect of Parameters on the Tool Life

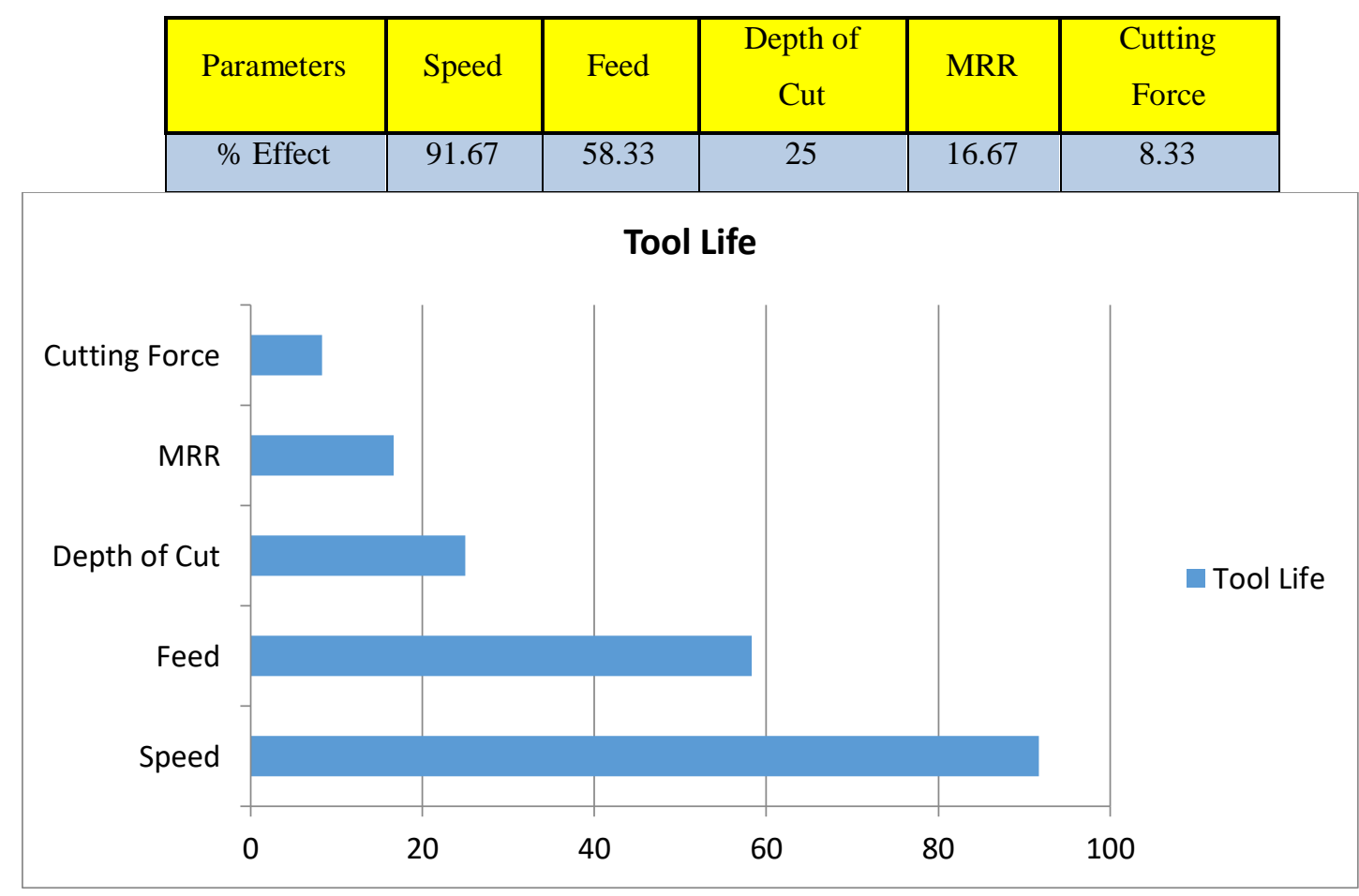

FIGURE 4 Graph chart for Effect of Parameters on The Tool Life 
From the above values, we can say that speed affects the tool life followed by feed rate. Third largest parameter is depth of cut followed by MRR and cutting force.

\section{Conclusion}

From the literature review above it is known that Several approaches are employed to minimise production time and maximise tool life by optimising parameters of cutting asCutting speed, feed rate, cutting depth, instrument angle, noseRadius, Fluid Cutting, etc. Among these approaches,The Taguchi process is considered to be the most commonly usedSystem used. The implementation of other approaches such as Grey Relation Analysis, ANOVA, Multiple Regression Analysis, Response Surface Method and The Artificial Neural Network is developing increasingly. In optimization of production time and tool life is found to be the most Significant factor followed by Feed Rate, Depth of cut and cutting speed.

\section{Reference}

[1] AhmetHasçalıkandUlaşÇaydaş, "Optimization of turning parameters for surface roughness and tool life based on the Taguchi method", Int J AdvManufTechnol,(2008), 38:896-903.

[2] HamdiAouici, Mohamed AthmaneYallese ,BrahimFnides , KamelChaoui andTarekMabrouk, "Modeling and optimization of hard turning of X38CrMoV5-1 steel with CBN tool: Machining parameters effects on flank wear and surface roughness", Journal of Mechanical Science and Technology, 25 (11) (2011), 2843-2851.

[3]Asutosh Panda, SudhansuRanjan Das andDebabrataDhupal, "Surface Roughness Analysis for Economical Feasibility Study of Coated Ceramic Tool in Hard Turning Operation”, Process IntegrOptim Sustain, (2017), 41660-017-0019-9.

[4] Samir Khamel, NouredineOuelaa andKhaiderBouacha, "Analysis and prediction of tool wear, surface roughness and cutting forces in hard turning with CBN tool", Journal of Mechanical Science and Technology, 26 (11), (2012), 36053616.

[5] A. T. Abbas, D. Yu. Pimenov, I. N. Erdakov, T. Mikolajczyk, E. A. El Danaf and M. A. Taha, "Minimization of turning time for high-strength steel with a given surface roughness using the Edgeworth-Pareto optimization method", Int $J$ AdvManufTechnol, (2017), 00170-017-0678-2.

[6]SitklAkincioğlu, HasanGökkaya andilyas Uygur, "The effects of cryogenic-treated carbide tools on tool wear and surface roughness of turning of Hastelloy C22 based on Taguchi method", Int J AdvManufTechnol,(2015), 00170-0157356-z.

[7] Ramanuj Kumar, Ashok Kumar Sahoo, Purna Chandra Mishra and Rabin Kumar Das, "Comparative study on machinability improvement in hard turning using coated and uncoated carbide inserts: part II modeling, multi-response optimization, tool life, and economic aspects", Adv. Manuf., (2018), s40436-018-0214-0.

[8] Miguel MandúBonfá, Éder Silva Costa, Wisley Falco Sales, Fred LacerdaAmorim, Luis Henrique Andrade Maia andÁlisson Rocha Machado, "Evaluation of tool life and work piece surface roughness in turning of AISI D6 hardened steel using PCBN tools and minimum quantity of lubricant (MQL) applied at different directions", The International Journal of Advanced Manufacturing Technology, (2019), s00170-019-03619-z.

[9] NivaldoLemosCoppini, Anselmo Eduardo Diniz, Felipe SoaresLacerda, Marcelo Bonandi andElesandro Antonio Baptista, "Internal turning of sintered carbide parts: tool wear and surface roughness evaluation", Journal of the Brazilian Society of Mechanical Sciences and Engineering, (2018), s40430-018-1139-z.

[10]SanjeevSaini, Inderpreet Singh Ahuja and Vishal S. Sharma, "Influence of Cutting Parameters on Tool Wear and Surface Roughness in Hard Turning of AISI H11 Tool Steel using Ceramic Tools", International Journal of Precision Engineering and Manufacturing, (2012), Vol. 13, No. 8, pp. 1295-1302.

[11] T. Tamizharasan, T. Selvarajand A. NoorulHaq, "Analysis of tool wear and surface finish in hard turning", Int $J$ AdvManufTechnol, (2006), 28: 671-679.

[12] Jing Sheng, "A modeling method for turning parameters coupling based on minimum cutting tool wear", Int $J$ AdvManufTechnol, (2015), 76:705-712.

[13] P. Sivaiah, "Evaluation of hybrid textured tool performance under minimum quantity lubrication while turning of AISI 304 steel", Journal of the Brazilian Society of Mechanical Sciences and Engineering, (2019), 41:571.

[14] Mozammel Mia and Nikhil RanjanDhar, "Optimization of surface roughness and cutting temperature in highpressure coolant-assisted hard turning using Taguchi method", Int J AdvManufTechnol, (2016), s00170-016-8810-2.

[15] D.K. Ojhaand U.S. Dixit, "An economic and reliable tool life estimation procedure for turning", Int $J$ AdvManufTechnol, (2005), 26: 726-732.

[16] Muhammad Younas, Syed Husain Imran Jaffery, Mushtaq Khan, Muhammad Ali Khan, Riaz Ahmad, AamirMubashar andLiaqat Ali, "Multi-objective optimization for sustainable turning Ti6Al4V alloy using grey relational analysis (GRA) based on analytic hierarchy process (AHP)", The International Journal of Advanced Manufacturing Technology,(2019), s00170-019-04299-5.

[17] Denis Boing, Fernando Luiz Castro and Rolf Bertrand Schroeter, "Prediction of PCBN tool life in hard turning process based on the three-dimensional tool wear parameter", The International Journal of Advanced Manufacturing Technology, (2019), s00170-019-04509-0. 
[18] S.P. Palaniappan, K. Muthukumar, R.V. Sabariraj, S. Dinesh Kumar and T. Sathish, "CNC turning process parameters optimization on Aluminium 6082 alloy by using Taguchi and ANOVA", Materials Today: Proceedings, (2019), 2214-7853.

[19] Manu Ravuri , Y. Santhosh Kumar Reddy and D. HarshaVardhan, "Parametric optimization of face turning parameters for surface roughness on EN 31 material using RSM and Taguchi method", Materials Today: Proceedings, (2020), 2214-7853.

[20] Mustafa Kuntog `u andHaclSag `lam, "Investigation of progressive tool wear for determining of optimized machining parameters in turning”, Measurement, 140 (2019), 427-436.

[21] IlhanAsiltürkand HarunAkkus, "Determining the effect of cutting parameters on surface roughness in hard turning using the Taguchi method”, Measurement, 44 (2011), 1697-1704.

[22] D. Philip Selvarajand P. Chandramohan, M. Mohanraj, "Optimization of surface roughness, cutting force and tool wear of nitrogen alloyed duplex stainless steel in a dry turning process using Taguchi method”, Measurement, 49 (2014), 205-215.

[23] Murat Sarlkaya andAbdulkadirGüllü, "Taguchi design and response surface methodology based analysis of machining parameters in CNC turning under MQL”, Journal of Cleaner Production, 65 (2014), 604-616.

[24] W.H. Yang and Y.S. Tarng, "Design optimization of cutting parameters for turning operations based on the Taguchi method”, Journal of Materials Processing Technology, 84 (1998), 122-129.

[25] Murat Sarlkaya andAbdulkadirGüllü, "Multi-response optimization of MQL parameters using Taguchi-based GRA in turning of difficult-to-cut alloy Haynes 25”, Journal of Cleaner Production, (2014), 1-11.

[26] NilrudraMandal, B. Doloi , B. Mondaland Reeta Das, "Optimization of flank wear using Zirconia Toughened Alumina (ZTA) cutting tool: Taguchi method and Regression analysis”, Measurement, 44 (2011), 2149-2155.

[27] Ashok Kumar Sahoo andSwastikPradhan, "Modeling and optimization of Al/SiCp MMC machining using Taguchi approach”, Measurement, 46 (2013), 3064-3072.

[28] R. Suresh, S. Basavarajappa and G.L. Samuel, "Some studies on hard turning of AISI 4340 steel using multilayer coated carbide tool", Measurement, 45 (2012), 1872-1884.

[29] Abram Plet, GouthamanNithyanand, FarbodAkhavanNiaki andLaine Mears, "Identification of optimal machining parameters in trochoidal milling of Inconel 718 for minimal force and tool wear and investigation of corresponding effects on machining affected zone depth”, Journal of Manufacturing Processes, 43 (2019), 54-62.

[30] M. Anthony Xavior and M. Adithan, "Determining the influence of cutting fluids on tool wear and surface roughness during turning of AISI 304 austenitic stainless steel”, Journal of Material Processing Technology, 209 (2009), $900-909$.

[31] Dong Min Kim, Ineon Lee, Sun Keel Kim, Bo Hyun Kim andHyungWook Park, "Influence of a micro patterned insert on characteristics of the tool-work piece interface in a hard turning process", Journal of Materials Processing Technology, 229 (2016), 160-171. 